\title{
Rafting the Ethical Rapids
}

\author{
Julie Collier $\cdot$ Mary Rorty $\cdot$ Christy Sandborg
}

\section{Introduction}

Clinical ethics committees have a long tradition in hospitals, and since 1993 have been required for accreditation by any hospital of more than 200 beds. Their role has typically included assistance with the development and review of policies and guidelines affecting the care of individual patients; education in ethics for the physicians and clinical staff who serve patients; and case consultation on ethical issues that arise in the care of patients.

The typical hospital ethics committee is a group of 10 to 30 members, depending upon the size of the institution, comprised of medical care providers, community representatives, ethicists, and chaplaincy who have expressed interest in serving on the committee. Committee members can serve as resources to their clinical services and as conduits of communication between the committee and the institution's functional units on controversial issues that have ethical implications.

The most frequent call on an institutional ethics committee is its function in case consultation. When disagreements arise between clinicians, between different teams who are involved in the care of the same patient, or between clinicians and family members about the plan of care for a particular patient, the ethics committee can provide advice, information or mediation to those struggling with the conflict. Ethics committee recommendations are typically advisory only, with the decisions remaining in the hands of those responsible for the patient's care.

But particular cases can move participants away from the individual level. Clinical cases often have organizational implications. In the course of resolving an individual case, structural problems within the institution often surface, whether staffing issues, problems with unit organization, or the

Julie Collier, Ph.D., Stanford University, Stanford, CA 94305; email: julie.collier@ stanford.edu.

Mary V. Rorty, Ph.D., 82 Peter Coutts Circle, Stanford, CA 94305; email: mvr2j@stanford.edu.

Christy Sandborg, M.D., Stanford University, Stanford, CA 94305; email: sandborg@ stanford.edu. 
absence of a policy that will provide guidance to clinicians. The resolution of a problematic bedside issue may require an institutional, rather than an individual, solution. And typical clinical ethics concerns, such as privacy and confidentiality of information, communication and disclosure, truth-telling, informed consent or conflicts of interest, often have organizational analogues. ${ }^{1}$

In the last two decades, the entire healthcare sector has undergone rapid and often confusing changes in hospital organization, reimbursement patterns and care delivery that have placed new stresses on internal organization. In 1995 the Joint Commission on Accreditation of Hospital Organizations added to their conditions for accreditation the requirement that healthcare organizations include an 'organization ethics' function in their internal processes (JCAHO, 1995, pp. 95-97). How this requirement should be met remains unspecified, and organizations have responded in various ways. Some organizations have added a separate committee to their ethics program. ${ }^{2}$ In other hospitals one individual has been designated to assume that role. ${ }^{3}$ For many, the requirement for 'organization ethics' has simply served as a reminder to already-constituted committees that calls for an ethics consult may often represent needs and require responses that extend beyond the initial bedside encounter that prompted the call.

Generalizations about what an organization ethics process would look like and how it should be instituted are often empty or ineffectual. But the requirement itself suggests that attention to ethics in institutions requires more than dispute resolution in individual cases. Case studies-instances of how individual committees manage to ride the waves of change that are buffeting healthcare organizations in America (and Canada) today-can offer encouraging examples of how ethics services can thrive in a time of transition. ${ }^{4}$ This paper presents a case study of how one ethics committee is attempting to meet the ethical demands of the new century.

Our committee serves a busy (250) bed children's hospital affiliated with an academic medical center, and with 30 members is relatively large, with about half of the members present at any given meeting. We typically receive 8-10 formal consults a year, in addition to less-formal "curbside" consults or requests for one or two members of the Committee to attend a patient care meeting. A member of the Committee also routinely attends interdisciplinary rounds in the pediatric intensive care unit and the cardiovascular surgery intensive care unit. Our Committee operates on a 'moral community' model: for formal consults, the whole Committee is notified and as many as can attend the resulting meeting with the family and team members. ${ }^{5}$ Service on the Committee is voluntary and uncompensated, and there is little turnover among our members. 
An ethics committee that is well integrated into the institution can serve as a barometer or early warning system for developing problems. A change in the number or pattern of consults, such as a rise in the number of consults from a particular unit or service, is often a reflection of a larger problem or conflict within the organization. These are the ethical "canaries in the coal mine" that point to circumstances that may jeopardize the ethical health of the organization. Over the past five years our committee has undertaken several initiatives aimed at addressing organization dilemmas in our institution, and in the process, the role of our committee has evolved beyond case consultation.

\section{Healing and Comfort}

One example of the "distress signal" function of ethics consults was a cluster of consults regarding management of post-operative pain in solid organ transplants. This prompted a multidisciplinary effort to understand the issues surrounding this problem. The PICU nursing staff was concerned about the degree of post-operative pain that patients suffered following their transplant. Their inability to ease their patients' discomfort caused significant professional distress. The transplant surgeons, on the other hand, had significant concerns that pain medications could jeopardize the immediate post-operative success of the transplant by compromising blood pressure through narcotic induced hypotension.

The Ethics Committee recommended the formation of a taskforce to review the issues associated with post operative pain in pediatric liver transplants. Through this process a comprehensive intervention plan was developed that included pre-operative parental education, nonpharmacological pain control modalities, careful monitoring of pain scores and a judicious increase in the use of narcotic and non-narcotic pain control medications. This comprehensive approach to pain led to better pain control with no adverse effects on the success of the transplants. Outcomes measured included change in pain scores pre- and post-intervention, parental satisfaction with pain management, change in time to extubation, length of stay in the ICU, and total length of stay. Results demonstrated a significant improvement in pain scores post-intervention, and a trend (although not significant) toward shorter PICU stays.

\section{Eligibility and Disability}

Our institution is a major transplant center, and transplant eligibility cases have come before our Committee at the request of the transplant teams or 
other providers. The most common conflicts in these cases centered on questions of the role that social, psychological, economic, and cultural barriers should play in the determination of eligibility. In addition, the impact of developmental disability on listing decisions was a common dilemma brought to the Committee's attention. These troubling cases pit the obligation to be "good stewards" of a very scarce resource against the principles of beneficence and justice.

To respond to the general issues regarding ethical concerns in transplant eligibility, a taskforce was formed, consisting of members from the ethics committee and representatives from the transplant services. Literature searches and a survey of our peer institutions revealed an absence of guidance, as well as considerable variation in practice throughout the pediatric transplant community. A survey of other programs suggests that candidacy in the face of developmental delay is a contentious issue across the country.

After a year of monthly meetings the taskforce produced guiding principles for determining transplant eligibility, dealing with the ethical issues in general terms. These principles are designed to provide guidance on ways to ensure that the ethical principles of beneficence, justice and autonomy have been considered in each decision, particularly when there are social, economic or cultural barriers, developmental delay, or significant behavioral problems. The next step will be to have the representatives of each transplant team take these guidelines back to their respective teams for review and endorsement. The commitment of some members of the transplant services, and their involvement in our process, has strengthened the feeling of community with what is seen in some institutions as an isolated fiefdom. In the course of the process, a grant was received to hold a national consensus conference on the ethics of determining eligibility for transplant of cognitively impaired children, calling attention to, and seeking to address, variations in practice at a national level.

\section{No Room at the Inn}

The success of many of our hospital's programs has lead to the unfortunate dilemma of too few hospital beds. The stress associated with the struggle to ethically allocate a vital limited resource has lead to clusters of ethics consults at different times, each cluster suggesting the need for a slightly different organizational solution.

One issue that emerged several years ago was the stress on the system that resulted from a combination of limited PICU beds and many technologically dependent children who had prolonged ICU stays, resulting in decreased 
access to ICU care for other patients. Expanding the unit might be a longterm solution — but that might not prevent the reappearance of the shortfall.

The ethics committee resolved to form an ad hoc task force-the Hospital to Home project - to figure out if there were structural issues causing problems, what they could be, and what might alleviate them. The membership of the $\mathrm{H} 2 \mathrm{H}$ taskforce varied from task to task and from meeting to meeting, as various resources in the institution, and in the wider community were consulted, but the core of the group was drawn from volunteers from the ethics committee.

The first exploratory stage suggested that the problem was not so much the raw number of beds, but an absence of resources to care for these children in the community. Problems often surfaced at the moment of discharge: the bed in a sub-acute institution to which the child was to be transferred was itself unavailable, the technological support that would allow the child to be sent home had not yet arrived, the home health agency did not have available staff with sufficient training to handle complex pediatric medical management, the available equipment turned out to be different than that used in the hospital, the parents at the last minute felt themselves to be (or were felt by the staff to be) unprepared to handle medical management at home of a complex case. The next exploratory stage utilized staff resources to survey extramural community resources. The loudly-proclaimed national nursing shortage proved in our community, as in so many others, to stem in part from a combination of low pay and high cost of living, and especially, in northern California, the cost of housing. There were some cases of mismatch of training and available equipment.

But talking to representatives of community home health agencies revealed a more surprising, and perhaps more easily addressed issue: compared to some of our peer institutions, the clients referred by our hospital to the agencies, especially ventilator-dependent children, and their families, were less prepared for the transition from hospital to home. Our institution could do little alone to solve a national nursing shortage, but we certainly could do something to improve our internal processes of preparing parents and families to care for their technologically dependent children, and by so doing could increase patient and family satisfaction, improve the quality of care, and increase the accuracy of predictions of the availability of an ICU bed.

The taskforce met monthly for the next year, doing literature searches on best practices from other institutions, talking to affected stakeholders about what needed to be done, and coordinating with other committees within the institution that worked on related issues. At the end of that year the taskforce produced discharge planning recommendations for technologically 
dependent children, as well as a detailed plan for the dissemination of these recommendations throughout the institution and the education of the people responsible for implementing it. ${ }^{6}$ In the process various supportive procedures and structures were formalized in the most affected units, facilitating things like peer-education for parents of children with specific diagnoses and designating both space and staff members with particular expertise for parent education. One of the most interesting research projects initiated by the taskforce was a retrospective analysis of our own treatment patterns which revealed the financial implications of delays in discharge, confirming our committee's conviction that ethically appropriate care is not only more efficient, but also more cost effective. Much of the material generated in this project was utilized in a much larger institutional initiative to evaluate and improve the entire in-patient journey from admission to discharge.

\section{A Period of Rapid Growth}

Growth and change can be as much a sign of health in an institution as in an individual. Rapid change, however, can stress a system, leading to decreases in both function and morale. A period of rapid growth at our institution was heralded by the arrival of a new program that was to bring about a significant increase in patient volume. Although vital to the long term viability of our hospital, the speed of the change left many services struggling to meet the increased demand. The Ethics Committee noted an increase in requests for consults from the units and services most affected by the changes.

While some of the issues prompting these consults were unavoidable (and typically temporary) "growing pains" associated with change, some themes emerged that suggested a breakdown of communication within different levels of the organization. A conscientious ethics committee feels some responsibility for the ethical climate of its institution, and the quality, and quantity, of communication within the organization is one of the best guarantors of a positive ethical climate. ${ }^{7}$ Threats to staff morale are threats to the quality of care available in an institution, and in this case an otherwise positive improvement in the services the institution could offer was shadowed by the way some of the changes were implemented.

As a result of recommendations by the Ethics Committee, two changes were initiated in our institution. The membership of the Ethics Committee, which already included members from quality assurance and risk management, was expanded to include the Chief of Pediatrics, and a new committee was formed within the institution, the Physicians Operations 
Committee, representing both physician leadership and administrative leadership. This Committee was established with the specific charge of proactive planning: considering the impact on affected stakeholders of proposed changes in hospital operations, and figuring out how to minimize adverse effects. One of the co-chairs of the Ethics Committee sits on that committee.

\section{Allocating Beds}

Improving discharge planning cannot solve all the problems of space in a busy institution. Despite efforts to increase capacity in our hospital, beds have continued to be a limited resource, exacerbated by the typical seasonal fluctuations in admissions. Another wave of concerns brought to the attention of the Ethics Committee focused on issues of distributive justicehow do you decide who gets the bed? Several years after the Home-toHospital taskforce completed its task, the Operations Committee formed a working group to develop priorities for admissions in times of high census. The objective was to facilitate a process to manage the use of all inpatient beds that was fair, ethical, feasible, and consistent with the mission and vision of our institution. The taskforce, which one of the co-chairs of our Committee chaired, was composed of 10 physicians and 3 administrators, and met biweekly.

The problem facing the working group was setting thoughtful priorities in admissions, considering the various demands on a busy hospital that explicitly commits to family-centered care. Candidates for admission can be local or regional-and sometimes, for innovative or high risk procedures, national and beyond. Emergency care, elective treatments that require the high level of care available in our institution, innovative procedures, and research all have a role to play. The Committee wanted to guard against arbitrary decision making, promoting consistent and impartial decisions and aiming for open and transparent decisional processes. The ethical imperative of the individual doctor/patient bond-fidelity to established relationshipswas an important governing condition.

After seven months of discussion, the working group developed an order of priorities and a decision tree for admission prioritization. The severity of illness ranked first as a consideration, followed by fidelity to the medical staff, those community and hospital based physicians most closely attached to the institution, whose patients will receive priority. Loyalty to the immediate community (the counties geographically proximate to our institution) comes next, with constant attention to the question of level of expertise required and whether there is alternate placement that could as 
adequately meet the needs of a given patient.

Decision trees were established for emergency admissions or transfers under the Emergency Medical Treatment and Active Labor Act, which take priority, and for scheduled surgeries and admissions; for the PICU and CVICU; and for the hospital's general care units. In the process of developing priorities, the working group suggested changes in processes and structures that would delegate specific responsibility for the decisions, as well as suggesting processes by which they would be made. These suggestions have significantly improved communication about expectations and accountability to all affected stakeholders.

\section{Conclusion}

Members of all the health professions, and the institutions themselves, are committed to the ethical practice of medicine. For that reason, specific ethics services within institutions can seem redundant, or be compartmentalized, or are consulted only in times of crisis. But the salience of ethical considerations in decisions at all levels, and attention to the alignment of values across the functional units of the institution, are important contributions that a high-functioning ethics committee can make to its hospital. In times of change, no committee can rely entirely on past precedents or habits of action. The impact of change ripples throughout the institution, affecting all aspects of institutional function, and paying attention to changing conditions contributes to the relevance of the ethics committee.

The success, level of activity, and degree of respect within the institution of any committee depends upon innumerable individual variables: the composition of the committee, the prestige within the institution of its most active members, its track record and history in the institution. But one of the factors key to the success of any ethics committee is the attitude of the institution's leadership. The success of our Committee's initiatives would not have been possible without the support of an administration that is genuinely invested in the ethical health of our organization.

\section{Acknowledgement}

The authors would like to acknowledge the support of Lucile Packard Children's Hospital administrative leadership, especially Christopher Dawes, Susan Flanagan, Pamela Wells and Alexandria Combs. 


\section{NOTES}

1 What protection for patient anonymity does the system allow for those who have authorized access? What happens to information gathered for administrative, epidemiological or research purposes? What rules govern institutional disclosure of policies, proprietary information or practitioner statistics to patients? Other institutions? The community? (Spencer, Mills, Rorty and Werhane, 2000, pp. 46-48).

2 The University of Virginia has had an ethics consult service as a subcommittee, meeting weekly and reporting to the institution ethics committee, for over 20 years. In 1998 they formed an organization ethics subcommittee, which also reports to the institution committee.

3 A large system of Catholic hospitals in the mid-west, for instance, has a designated 'organization ethics' educator who runs workshops in each of the system's hospitals. Catholic Healthcare West has a vice president for 'ethics and justice education,' a position with responsibilities for over 40 hospitals in the system.

4 The most comprehensive approach to ethical services in healthcare institutions is being developed by the Veterans Administration health system. They are developing and piloting an 'integrated ethics' program that coordinates three levels of ethical emphasis in each member institution: 1) bedside clinical consultation on patient care issues; 2) an organization level 'preventive ethics' program designed to address systemic and structural impediments to ethical practice; and 3) an ethical leadership program designating an organization leader to oversee and coordinate ethics implementation and education throughout the institution (see Fox and Tulsky, 2005).

5 The most common models additionally include the 'lone ranger'-one person designated by the institution as 'the ethics guy' who is assisted on an ad hoc basis by committee members; or an outside paid ethics 'expert' who rounds in the hospital on a regular basis and reports to the ethics committee.

6 Opening with an overview of elements needed for medically safe, efficient and family-friendly discharge, the document proceeds to detail the responsibilities of the attending physician, primary subspecialty multidisciplinary team, residents, case manager, floor nursing, ancillary services, home care agencies, primary care physician and family, and included a Parent/Family Competency Checklist.

7 'Culture' and 'climate' are often used interchangeably in the management literature to refer to internal characteristics of organizations (see Denison, 
1996). As we use it here, ethical climate refers to the alignment of values and degree of concordance between the leadership and their constituencies.

\section{REFERENCES}

Fox, E. \& Tulsky, J.A. (2005). Recommendations for the ethical conduct of quality improvement. Journal of Clinical Ethics, 16(1), 61-71.

Denison, D.R. (1996). What is the difference between organizational culture and organizational climate? A native's point of view on a decade of paradigm wars. Academy of Management Review, 21, 619-54.

Joint Commission on Accreditation of Healthcare Organizations (1995). Patient rights and organizational ethics. Comprehensive manual for hospitals. Oakbrook Terrace: JCAHO.

Spencer, E.M., Mills, A.M., Rorty, M.V., \& Werhane, P.H. (2000). Organization ethics in healthcare. New York: Oxford University Press. 